\title{
Learning Processes and Study Strategies Influential to College Adjustment
}

\author{
Katharine S. Adams, Jennifer E. Breneiser
}

This study investigated relationships between entry-level learning processes and study strategies and student adaptation to college. A regression model consisting of the Learning and Study Skills Inventory (LASSI; Weinstein \& Palmer, 2002) subscales and GPA significantly predicted student adaptation to college as measured by the Student Adaptation to College Questionnaire (SACQ; Baker \& Siryk, 1999). The attitude and anxiety subscales emerged as significant predictors in this model. Correlational results indicated that attitude and anxiety were significantly correlated with four specific aspects of college adaptation (i.e., academic, personal-emotional, or social adjustment; and institutional attachment). Attitude was most strongly correlated with academic adjustment. Anxiety was most strongly correlated with personal-emotional adjustment. Consideration of these findings provides practical insights into the college adjustment process. Implications are discussed and suggestions for orientation and retention programs are offered.

\section{Introduction}

Student retention remains a pressing concern for colleges and universities as attrition rates have remained high and relatively unchanged for several years (ACT, 2015; U.S. Department of Education [DOE], 2016). Recent statistics indicate that among first-time degree-seeking undergraduates at degree-granting postsecondary institutions, approximately a quarter (26\%) did not return the following academic year (DOE, 2016). Additionally, almost half (41\%) of full-time undergraduate students who began seeking a bachelor's degree at a four-year institution did not complete the degree within six years (DOE, 2016). To combat the problem of attrition, efforts to increase retention rates have included college orientation programs to introduce students to available academic resources (e.g., tutoring), faculty mentor programs, freshman learning communities, and social activities (e.g., Greek life, intramural sports) to connect students to each other on campus (Valentine et al., 2011). At-risk groups targeted by such programs include the economically disadvantaged, minority students, women, non-traditional students, and students with disabilities (Seidman, 2005, p. xii).

Student attrition appears to be most problematic during the first few years of college as students try to adjust and adapt to their new environments. Therefore, it is important to consider the student adaptation process and factors that may

Katharine S. Adams, Ph.D. and Jennifer E. Breneiser, Ph.D. are Associate Professors in the Department of Psychology, Counseling, and Family Therapy at Valdosta State University, Valdosta, GA. This research was supported in part by a faculty research grant from Valdosta State University. 
influence student adaptation to college, including entry-level learning processes and study skills. By focusing on learning processes and study strategies, which have been shown to respond quite well to intervention (Weinstein \& Palmer, 2002), and understanding how strategy use contributes to student adaptation to college, educators could simultaneously target interventions to remediate study strategies identified as weak, promote student adaptation to college, and facilitate overall college success.

\section{Student Adaptation to College}

Some of the most widely cited theoretical frameworks of college attrition (Bean, 1980; Kuh, Kinzie, Buckley, Bridges, \& Hayek, 2006; Pascarella, 1980; Spady, 1970; Tinto, 1993) reflect relationships with student adjustment (Crede \& Niehorster, 2012). During the first few years of college, students face the challenges of separating from family to experience greater autonomy, initiating new relationships, and adapting to the rigors of college coursework (Brooks \& DuBois, 1995). How students adapt to the many facets of college life has been shown to be an important factor in academic success and is highly predictive of college grades and retention (Crede \& Niehorster, 2012).

Some colleges have implemented retention programs influenced by various theoretical perspectives on student adjustment. For example, Tinto's (1993) interactionalist theory identifies three primary reasons students may leave the university, including academic difficulties, problems with educational and/ or occupational goal accomplishment, and the inability to integrate into the intellectual and social life of the institution. Numerous studies document the importance of academic and social interactions to college student retention (Xu \& Webber, 2018). Other researchers (Braxton, 2003; Braxton, Hirschy \& McClendon, 2004) have proposed revisions to Tinto's theory that highlight the responsibilities of the institution in providing quality teaching, academic advising, and other functions to encourage student engagement (Xu \& Webber, 2018). Student engagement includes an interaction of student behaviors (e.g., study habits, peer involvement, interaction with faculty, time management strategies, motivation) and institutional conditions (e.g., first-year experience, academic and peer support, campus environment, and teaching/learning approaches) (Kuh et al., 2006). Student engagement facilitates the student's successful transition to college life.

Schlossberg (1981) identified a general model of human adaptation to transition, which identifies three different types of transitions; anticipated, unanticipated, and non-events. Schlossberg's transition theory has been applied to many different life events, including students arriving at college for the first time (e.g., Chickering \& Schlossberg, 2002). Chickering and Schlossberg (2002) describe four sets of factors (the four S's) that influence a student's ability to cope with college transitions, including the situation, self (personal characteristics and psychological resources), social support, and strategies or coping responses. Each of these components plays a role in a student's successful transition to college, retention, and completion (Chickering \& Schlossberg, 2002). As part of their 
retention efforts, colleges have sought to measure how successfully students cope with the transition to college.

One of the primary instruments used to research college student transition is the Student Adaptation to College Questionnaire (SACQ; Baker \& Siryk, 1999). Baker and Siryk (1984) conceptualize student adaptation to college as a multidimensional construct including specific academic, social, and personalemotional adjustments, as well as institutional attachment. First, academic adjustment relates to a student's ability to cope with the educational demands characteristic of college. Similarly, social adjustment includes a student's ability to cope with the interpersonal-societal demands related to college. Personalemotional adjustment relates to a student's physical and psychological well-being during the adjustment process. Finally, institutional attachment includes the degree of satisfaction felt by a student in regard to college in general as well as the specific institution (Baker \& Siryk, 1986). These four dimensions reflect the four $S$ 's in Schlossberg's transition theory, with the academic and social adjustment scales relating to situation and support, the personal-emotional adjustment relating to the self, and the institutional attachment relating to strategies (Carter, Locks, \& Winkle-Wagner, 2013). They also reflect Tinto's theory by highlighting the importance of academic and social interactions in the success of college students (Carter et al., 2013). Baker and Siryk's (1986) taxonomy is useful because it accounts for the students who struggle to adapt and perform poorly on academic tasks, resulting in poor grades and withdrawal from the university due to academic reasons (Baker \& Siryk, 1986), as well as those who withdraw due to difficulties adjusting to the social and personal-emotional demands of college, or due to a weak affiliation with the institution (Rummel, Acton, Costello, \& Pielow, 1999; Tinto, 1993). The SACQ was used in the present study because it has proved useful as an assessment aid in counseling college students and in research.

There is certainly value in understanding the relationship between college adaptation and outcome variables such as grades and retention, but the ability to adapt successfully to college may be viewed an important outcome variable in its own right (Adams \& Proctor, 2010; Aspinwall \& Taylor, 1992; Brooks \& DuBois, 1995), and a number of researchers have attempted to identify viable contributors to student adaptation to college. For example, Crede and Niehorster's (2012) meta-analytic synthesis of the literature resulted in eight broad contributing categories, one of which included demographic characteristics such as minority status. Intuitively, from a person-environment perspective, it seems that those with a minority ethnic background would have lower levels of adjustment perhaps due to higher levels of prejudice and discrimination (Crede \& Niehorster, 2012). However, the meta-analysis found that while there was large variability in the social adjustment for minority students, minority status was largely unrelated to overall adjustment to college (Crede \& Niehorster, 2012). Other contributing categories included prior achievement, experiences at college, core self-evaluations and traits, state and trait affect, coping style, social support, and relationships with parents (see summary by Crede \& Niehorster, 2012). The present research considers student adaptation to college an important outcome variable with important 
implications for student attrition and retention.

\section{Learning Processes and Study Strategies}

As part of their retention efforts, some colleges routinely assess entry-level learning processes and study skills in hopes of identifying and remediating at-risk students (Kwong \& Wong, 2009; Prevatt, Petscher, Proctor, Hurst, \& Adams, 2006). Learning processes and study strategies may include thoughts, behaviors, attitudes, motivations, and beliefs that relate to successful college learning (Weinstein \& Palmer, 2002). Some strategies may be readily apparent and others more hidden (Weinstein \& Palmer, 2002). Strategy use involves the utilization of academic skills such as information processing, selecting main ideas, and test-taking strategies, but students must also be willing and able to exert necessary effort, cope effectively with anxiety, and maintain a positive attitude and motivation. Finally, selfregulation skills are critical in maintaining concentration, engaging in self-testing, making use of study aids, and effective time management (Weinstein \& Palmer, 2002). Several researchers have identified the importance of learning processes and study strategies at the time of college entry in later student success (Carson, 2011; Marrs, Sigler, \& Hayes, 2009; Nist, Mealey, Simpson, \& Kroc, 1990; Reaser, Prevatt, Petscher, \& Proctor, 2007; Weinstein \& Palmer, 2002). Motivation specifically has been shown to be an important discriminator between high and low achievers (Carson, 2011; Marrs et al., 2009). Students demonstrating weak entry-level strategies (i.e., skills, will, and self-regulation) may be underprepared for postsecondary education and thus more likely to encounter difficulties (Weinstein \& Palmer, 2002). The Learning and Study Strategies Inventory - 2nd Edition (LASSI; Weinstein \& Palmer, 2002) was used in the present study because it is a widely used assessment of students' use of learning and study strategies related to college success.

The LASSI (Weinstein \& Palmer, 2002), based on Weinstein's Model of Strategic Learning (Weinstein, Acee, \& Jung, 2010), assesses students' awareness about the use of learning and study strategies related to skill, will, and self-regulation. Skill refers to critical knowledge about learning strategies and how to use them (i.e., information processing, selecting main ideas, test strategies). Will refers to the motivation and affective components of strategic learning (i.e., anxiety, attitude, motivation). Self-regulation skills help students manage their learning and study environment (i.e., concentration, self-testing, study aids, time management). These three components of strategic learning are under a student's control and are needed to be effective and efficient learners in varied educational environments (Weinstein, Acee, \& Jung, 2011).

Widespread use of the LASSI by college orientation programs, advisors, and learning centers is related to its diagnostic and prescriptive utility. The LASSI may be used diagnostically to provide students with an assessment of their strengths and weaknesses with regard to each one of 10 learning and study strategies. Additionally, because the LASSI provides feedback about areas where students may be weak and need to improve, it may be used as a basis for planning remediation 
or enrichment. The LASSI can be used to raise awareness about students' use of learning and study strategies, develop a plan to capitalize on strengths and remediate weaknesses, and help students become more strategic learners. Research has repeatedly demonstrated that the learning and study strategies assessed by the LASSI contribute significantly to success in college, and more importantly, they can be learned or enhanced through educational interventions, such as learning strategies and study skills courses (Weinstein \& Palmer, 2002).

A number of college orientation and retention programs target both entry-level learning processes and study strategies and a student's broader ability to adjust to the college experience. However, these programs remain relatively uninformed by research as to how these constructs may influence each other or be used in combination. By focusing on learning processes and study strategies, which have been shown to respond quite well to intervention (Weinstein \& Palmer, 2002), and understanding how strategy use contributes to student adaptation to college, educators could simultaneously prescribe interventions to remediate strategies identified as weak, promote student adaptation to college, and facilitate overall college success. Thus, the aim of the present research was to inform current postsecondary orientation and retention practices, by answering the following research questions:

1. Can specific learning processes and study strategies that students possess during the first two years of college be used to predict overall adaptation to the college experience?

2. Does the predictive ability of the specific learning processes and study strategies for overall student adaptation to college differ by achievement (i.e., GPA)?

3. What is the relationship between students' attitudes, their ability to cope with academic anxiety, and specific college adjustment processes (i.e., academic, social, personal-emotional, attachment)?

\section{Method}

\section{Participants}

Participants were postsecondary students in their first year (freshman) or second year (sophomore) of study at a regional university in the Southeastern United States $(N=162)$. The data were collected during spring, summer, and fall semesters. To increase homogeneity of the undergraduate student sample and improve interpretive ability of findings regarding adaptation to the college experience, only those students who self-identified as first year (freshman) or second year (sophomore) students were included in the data. Those participants that self-identified as juniors $(n=8)$ or abstained from answering the question on educational standing $(n=1)$ were removed from the sample. No students identified as seniors, or they would have been excluded, as well. Additionally, one student under the age of 18 , five students over the age of 25 , and one student who 
self-identified as married were excluded. Of the 16 participants removed from the sample, 11 were Caucasian, three were African American, one was Asian American, and one self-identified as other. Additionally, ten of the removed participants were female and six were male.

Of the 146 remaining participants (111 females, 35 males) included in the analysis, ages ranged from $18-22(M=18.97, S D=.81)$. Additionally, $45.20 \%$ $(n=66)$ were Caucasian, $43.80 \%(n=64)$ were African-American, $.70 \%(n=1)$ were Asian American, 4.10\% $(n=6)$ were Hispanic American, and 6.20\% $(n=9)$ self-identified as other. Of the participants, $54.10 \%(n=79)$ were Freshmen and $45.90 \%(n=67)$ were Sophomores. Furthermore, $19.90 \%(n=29)$ were taking honors classes, $22.60 \%(n=33)$ were on academic probation, and $10.30 \%(n=15)$ reported past academic suspension. Student cumulative grade point average (GPA) ranged from $0-4(M=2.70, S D=.95)$.

\section{Procedure}

Students with wide ranging achievement levels were recruited from general undergraduate courses, remedial courses, and honors courses with assistance from individual course instructors and graduate assistants. In obtaining informed consent, graduate assistants described the nature and purpose of the study and emphasized that participation in the research was completely voluntary. Extra credit for participation in the study or an alternate assignment (e.g., research article review) was given at the discretion of the course instructors. Graduate assistants distributed survey packets to students in groups in a classroom setting. Students completed the survey packets in approximately 35-40 minutes. Following completion of the survey packets, graduate assistants debriefed students and allowed them to ask questions pertaining to the research.

\section{Measures}

Survey packets were counterbalanced and included a demographic questionnaire, the Learning and Study Skills Inventory (LASSI; Weinstein \& Palmer, 2002), and the Student Adaptation to College Questionnaire (SACQ; Baker \& Siryk, 1999). The demographic questionnaire assessed age, gender, ethnicity, advanced placement or honors status, academic probation and/or suspension, cumulative hours completed, and grade point average. Academic information was verified by a review of student transcripts.

The LASSI (Weinstein \& Palmer, 2002) was used to assess students' awareness about and use of learning and study strategies, including thoughts, behaviors, attitudes, motivations and beliefs that relate to successful learning in postsecondary settings. The LASSI is an 80 item, self-report questionnaire. Each LASSI item is a statement that the student responds to on a 5-point scale ranging from "very much typical of me" to "not at all typical of me". Some items are reverse-scored. The LASSI yields 10 eight item subscales. Subscale items 
were summed and then converted to percentile scores using the hand-scoring procedures provided by the publisher. Percentile scores ranged from 1-99 compared to a normative group of college students. Scores at or above the 75th percentile level indicate an area of relative strength. Any score between the 50th and 75th percentile levels indicates an area that may need improvement. Any score at or below the 50th percentile level indicates an area of relative weakness. LASSI subscales include anxiety, attitude, concentration, information processing, motivation, selecting main ideas, self-testing, study aids, test strategies, and time management. A description of each subscale can be found in Table 1. The LASSI is a widely used measure of learning and study strategies with adequate psychometric properties (Cronbach's alpha $=.73$ to .89 ) for all ten subscales (Weinstein \& Palmer, 2002).

\section{Strategies Assessed by the 10 Scales of the Learning and Study Strategies Inventory}

Scale

1. Anxiety

2. Attitude

3. Concentration

4. Information Processing

5. Motivation

6. Selecting Main Ideas

7. Self-Testing

8. Study Aids

9. Test Strategies

10. Time Management

\section{Description}

Measures students' worry about school and their academic performance. Students who score low on this measure (indicating high anxiety) need to learn techniques for coping with anxiety.

Measures students' attitudes and interests in college and achieving academic success.

Measures students' ability to direct and maintain their attention on academic tasks.

Measures students' use of imagery, verbal elaboration, organization strategies, and reasoning skills as learning strategies to help learn new information and skills and to build bridges between what they already know and what they are trying to learn and remember.

Measures students' diligence, self-discipline, and willingness to exert the effort necessary to successfully complete academic requirements.

Measures students' skill at identifying important information for further study from less important information and supporting details.

Measures students' use of reviewing and comprehension monitoring techniques to determine their level of understanding of the information or task to be learned.

Measures students' use of support techniques, materials, or resources to help them learn and remember new information. Measures students' use of both test preparation and test taking strategies.

Measures students' use of time management principles for academic tasks. 
Student adjustment to college was measured using the Student Adaptation to College Questionnaire (SACQ; Baker \& Siryk, 1999). The SACQ is a 67-item, selfreport questionnaire. Each SACQ item is a statement that the student responds to on a 9-point scale ranging from "applies very closely to me" to "doesn't apply to me at all". Some items are reverse-scored. The SACQ yields a Full-Scale score as a summed index of overall adjustment to university, as well as four subscales measuring specific aspects of adjustment to college or university (i.e., academic adjustment, social adjustment, personal-emotional adjustment, and institutional attachment). The academic adjustment subscale measures a student's success in coping with the various educational demands characteristic of the college experience. The social adjustment subscale measures a student's success in coping with the interpersonal-societal demands inherent in adjustment to college. The personal-emotional adjustment subscale measures a student's intrapsychic state during his or her adjustment to college, and the degree to which he or she is experiencing general psychological distress and any associated somatic problems. Finally, the goal commitment/institutional attachment subscale measures a student's degree of commitment to educational-institutional goals and the degree of attachment to the particular institution the student is attending. Adjustment subscales include 24, 20,15, and 15 items respectively. Summed SACQ scores were converted to T-scores and percentiles using the hand-scoring procedures provided by the publisher and were based on the normative sample stratified by sex and semester of college. Percentiles were used in the current analysis. Scores below the 40th percentile are below average and those below the 30th percentile are low. Scores above the 60th percentile are above average and those above the $70^{\text {th }}$ percentile are high. The SACQ is a well-validated measure with adequate psychometric properties (Cronbach's alpha $=.77$ to .91 ) reported in several independent studies (Baker \& Siryk, 1999).

\section{Results}

Preliminary analysis determined that the proportion of missing data in the set was small and random. Participants with missing values on the variables of interest were not included in the analysis. A case analysis did not identify any problematic outliers. No serious violations of the correct fit, constant variance, and normality assumptions were identified. Finally, because none of the typical sources of violations of the independence assumption were present in the study, there was no reason to suspect violations of this assumption.

The analyses involved a standard multiple regression analysis to predict overall student adaptation to college using learning and study strategies (i.e., anxiety, attitude, concentration, information processing, motivation, self-testing, selecting main ideas, study aids, time management, and test strategies), cumulative GPA, and ethnicity as predictor variables for all students in the sample. However, consistent with Crede \& Niehorster (2012), ethnicity was not a significant predictor of student adaptation to college, and was thus removed from the model, and the model was re-run, excluding ethnicity. Follow-up bivariate correlational analyses 
were used to describe the relationship between attitude and anxiety and the four dimensions of student adaptation to college (i.e., academic, social, and personalemotional adjustment; and institutional attachment).

A multiple regression analysis was conducted to evaluate how well the LASSI subscales and cumulative GPA predicted SACQ total scores. The predictors for this analysis were the 10 LASSI subscales and cumulative GPA, while the criterion variable was the total SACQ score. The linear combination of LASSI subscales and cumulative GPA was significantly related to the SACQ total score, $F(11,129)$ $=11.01, p<.001$. The sample multiple correlation coefficient was .70, indicating that approximately $48 \%$ of the variance in the sample's SACQ total scores was accounted for by the linear combination of LASSI subscales and cumulative GPA. The coefficients for the model, including bivariate and partial correlation coefficients, are presented in Table 2.

\section{TABLE 2}

\section{Coefficients for Model}

$B \quad \beta \quad t \quad$ Bivariate $r$ Partial $r$

$\begin{array}{lccccc}\text { Cumulative GPA } & 3.96 & .13 & 1.81 & .24 & .16 \\ \text { LASSIP Anxiety } & .39 & .43 & 4.88^{* *} & .48 & .39 \\ \text { LASSIP Attitude } & .38 & .36 & 4.44^{* *} & .52 & .36 \\ \text { LASSIP Concentration } & .01 & .01 & .10 & .38 & .01 \\ \text { LASSIP Information Processing } & -.09 & -.09 & -1.16 & .13 & -.10 \\ \text { LASSIP Motivation } & .09 & .09 & .98 & .46 & .09 \\ \text { LASSIP Self-Testing } & .15 & .14 & 1.61 & .25 & .14 \\ \text { LASSIP Selecting Main Ideas } & .15 & .15 & 1.36 & .46 & .11 \\ \text { LASSIP Study Aids } & -.07 & -.07 & -.89 & .15 & -.08 \\ \text { LASSIP Time Management } & .08 & .09 & .86 & .33 & .08 \\ \text { LASSIP Test Strategies } & -.21 & -.21 & -1.84 & .42 & -.16\end{array}$

Correlations for select SACQ and LASSI subscales are presented in Table 3. Bivariate correlations between the subscales were positive, as expected, and the LASSI anxiety subscale was most strongly correlated with emotional adjustment $(r=.54$, $p<.001)$, whereas the LASSI attitude subscale was most highly correlated with academic adjustment $(r=.63, p<.001)$. 
TABLE 3

\section{Correlations for select SACQ and LASSI subscales}

$\begin{array}{lcccccccc}\text { Measure } & 1 & 2 & 3 & 4 & 5 & \mathbf{6} & \boldsymbol{M} & \boldsymbol{S D} \\ \text { 1. Academic } & & & & & & & & \\ \quad \text { Adjustment } & & & & & & & 50.27 & 26.50 \\ \text { 2. Social Adjustment } & .45^{* *} & & & & & & & \\ \text { 3. Personal/Emotional } & .58^{* *} & .46^{* *} & & & & & 48.71 & 30.72 \\ \text { 4. Institution } & .48^{* *} & .73^{* *} & .44^{* *} & & & & 47.71 & 30.18 \\ \quad \text { Attachment } & & & & & & & & \\ \text { 5. LASSI Anxiety } & .34^{* *} & .36^{* *} & .54^{* *} & .21^{*} & & & 39.26 & 31.01 \\ \text { 6. LASSI Attitude } & .63^{* *} & .23^{*} & .38^{* *} & .30^{* *} & .14 & & 31.04 & 26.86\end{array}$

${ }^{*} p<.05,{ }^{* *} p<.001$

\section{Discussion}

The first few years of college involve a difficult transition for some students (Baker \& Siryk, 1986) and student attrition is an ongoing concern for many colleges and universities (ACT, 2015; DOE, 2016). Students may leave college for a variety of reasons, including problems with academics, or poor adjustment to the emotional and/or social aspects of college life (Baker \& Siryk, 1999; Tinto, 1993). In response, colleges and universities have made strategic attempts to ease the difficult transition for students by providing a diverse array of programs and supports (e.g., college orientation programs, faculty mentor programs, freshman learning communities, and social activities) (Valentine et al., 2011). As part of their retention efforts, some programs assess entry-level learning processes and study strategies in hopes of identifying and remediating at-risk students (Kwong \& Wong, 2009; Prevatt et al., 2006). Such practices seem prudent given that weak learning processes and study strategies respond well to intervention (Weinstein \& Palmer, 2002) and given the importance of such strategies in overall student success (Carson, 2011; Marrs et al., 2009; Nist et al., 1990; Reaser et al., 2007; Weinstein \& Palmer, 2002). Retention efforts have also focused on easing the often difficult adjustment process for beginning college students, and research has identified several factors influential to how well a student adapts (Crede \& Niehorster, 2012). However, there is a dearth of information examining the relationship and potential impact of learning processes and study strategies specifically on student adaptation to college. This research was conducted to inform current post-secondary education retention practices by identifying where targeted efforts could be made 
to remediate specific learning strategies identified as most influential to student adjustment.

The results of the present study revealed that specific learning strategies and study skills may be used to predict student adaptation to college, a major contributor to student attrition. The regression model consisting of the 10 LASSI subscales and GPA significantly predicted student adaptation to college. Correlational results indicated that attitude and anxiety were significantly correlated with all four aspects of college adaptation (i.e., academic, personalemotional, or social adjustment; and institutional attachment), but the pattern and strength of the correlations varied. Consideration of these findings provides practical insights into the college adjustment process and indicates a need for additional research. The identification of two strong predictors of overall student adaptation to college prompted additional research questions related to the specific adjustment processes influenced by attitude and anxiety.

First, it is important to note that, while the regression model significantly predicted college adaptation overall, only the attitude and anxiety subscales emerged as significant predictors in this model. These two LASSI subscales relate to the "will" component of strategic learning (Weinstein, Acee, \& Jung, 2010) and measure the degree to which students worry about their academic performance as well as their attitudes and interest in college. However, motivation is the third subscale comprising the will component of the LASSI and it did not contribute significantly to the prediction. For the current sample of first and second year college students, those with a facilitative attitude and motivation to succeed based on college being relevant to life goals were better adjusted. This is expected because motivation has been shown to be an important discriminator of achievement in past research (Carson, 2011; Marrs et al., 2009).

Interestingly, the motivation subscale of the LASSI did not significantly contribute to the prediction of student adaptation to college. To understand these findings, one must carefully examine the nature of the motivation construct as measured by the individual scales of the LASSI. The attitude subscale of the LASSI assesses more global levels of motivation for college as it relates to life goals (e.g., I do not care about getting a general education, I just want to get a good job) and the motivation subscale of the LASSI pertains more to specific levels of motivation for individual tasks and assignments (e.g., When work is difficult I either give up or study only the easy parts; Weinstein \& Palmer, 2002). A student's attitude and general motivation for succeeding in school impacts their persistence when studying or engaging in difficult school-related tasks. If relationships between school and life goals (academic, personal, social, and work-related goals) are unclear, it may be difficult to maintain an attitude that promotes good work habits, concentration, and attention to school-related tasks (Weinstein \& Palmer, 2002). The mean attitude score for this sample of students was at the 31st percentile, meaning that participants' attitudes were less facilitative and students were less motivated to succeed in college than $69 \%$ of students represented in the LASSI normative data (Weinstein \& Palmer, 2002).

Follow-up correlational results indicated that attitude was significantly 
correlated with all four aspects of college adaptation (i.e., academic, personalemotional, and social adjustment; and institutional attachment), but was most strongly correlated with academic adjustment. Thus, a student's attitude, motivation, and understanding of how college relates to their life goals was proportionally related to their ability to cope specifically with the educational demands characteristic of the college experience.

In terms of retention efforts, it would be incorrect to assume that because students are enrolled and attending college, they understand the relevance of college to their life goals and that their attitude is facilitative. College students in this sample scored low on the attitude sub-scale and would likely benefit from working on higher-level goal setting and reassessing how college education fits into their future. In emphasizing these skills, students may reaffirm their motivation to take responsibility for their own learning and management of their study activities (Weinstein \& Palmer, 2002) and as this study suggests, improve their overall adaptation to the college experience.

In considering the remaining significant predictor of student adaptation to college in the model, anxiety, first and second year students who were more adept at managing their worry about school and their academic performance were better adjusted overall to the college experience. This is consistent with past research which demonstrates positive relationships between anxiety coping skills and the acquisition of knowledge (Warr \& Downing, 2000) and final course grades (Talbot, 1994). From a cognitive theoretical perspective, cognitive worry may manifest in negative self-statements. Negative thoughts, beliefs, and feelings about one's abilities, future, or the likelihood of success, may divert attention away from academic tasks and inward to self-criticism and irrational fears (Weinstein \& Palmer, 2002). Therefore, anxious students may have difficulty fulfilling their desired level of knowledge and skill because they are expending their cognitive energy on worrying. The mean anxiety score for this sample was at the 39th percentile, meaning that participants' abilities to cope with anxiety were weaker than the remaining 61\% represented in the national norms (Weinstein \& Palmer, 2002). This finding is consistent with other survey research reporting overwhelming feelings of anxiety in as much as $42 \%$ of male and $60 \%$ of female college students (American College Health Association, 2014). It seems that many beginning college students, including those in the current sample, struggle to cope with anxiety.

Follow-up correlational results indicated that anxiety was significantly correlated with all four aspects of college adaptation (i.e., academic, personalemotional, or social adjustment; and institutional attachment), but was most strongly correlated with personal-emotional adjustment. Thus, a student's ability to cope with anxiety when approaching academic tasks was proportionally related to their overall sense of psychological and physical well-being. Common emotional symptoms for students experiencing adjustment difficulties include sadness, hopelessness, lack of enjoyment, anxiety, and feeling overwhelmed, all of which may negatively impact school performance (American Psychiatric Association, 2013). Such students may benefit from developing techniques for 
coping with anxiety, reducing worry, and as this study suggests, improving their sense of wellbeing and adaptation to the college experience.

It is important to note that neither GPA nor the skill or self-regulation component subscales of the LASSI (i.e., information processing, selecting main ideas, test strategies, concentration, self-testing, study aids, time management) contributed significantly to the regression model. These results may seem counterintuitive in that we would expect students who struggle to adapt to perform poorly on academic tasks. However, while this is true for some students (Baker \& Siryk, 1986), many others who withdraw from college do so voluntarily and in good academic standings (Tinto, 1993).

These results illustrate the usefulness of adhering to a multidimensional taxonomy. This taxonomy is useful because it accounts for the students who struggle to adapt and who perform poorly on academic tasks, resulting in poor grades and withdrawal from the university due to academic reasons (Baker \& Siryk, 1986), as well as those who withdraw due to difficulties adjusting to the social and personal-emotional demands of college, or due to a weak affiliation with the institution (Rummel et al., 1999; Tinto, 1993). If retention programs target only academic variables, students who possess adequate study skills, effectively selfregulate, and perform well academically likely will not be identified as at-risk by instructors or advisors. Perhaps retention programs should focus more broadly on psychological issues related to the social and personal/emotional adjustment of students, specifically coping with anxiety and attitude.

Some limitations associated with the participant sample should be considered when interpreting and evaluating the results of this study. First, participants were predominantly female first and second year college students; therefore, there are inherent limitations in generalizing the findings to males. Nonetheless, there is value in studying a predominately female sample in that the number of women attending college is steadily increasing and the majority (56\%) of undergraduate college students are female (Institute for Women's Leadership, Rutgers University, 2008; U.S. Census Bureau, 2010). Additionally, while some researchers have identified gender differences (Enochs \& Roland, 2006; Li, Albert, \& Dwelle, 2014), a large meta-analytic study of adjustment to college as measured by the SACQ indicated that gender was largely unrelated to college adjustment (Crede \& Niehorster, 2012). Additionally, participants were from a regional university in the Southeastern United States where much of the area surrounding the university is considered rural and approximately $28 \%$ of students are first-generation college students (Pope, 2015). Approximately one third of participants indicated that one or both of their parents did not attend college ( $29 \%$ of mothers, $36 \%$ of fathers). Because first-generation students may receive less support from their families while attending college, yet may feel added pressure to be successful in college, they may be susceptible to doubts about their academic and motivational abilities and find it difficult to feel integrated socially and academically (Cushman, 2006).

Given the pervasive impact of attitude and anxiety on student adaptation to college, orientation and retention programs may choose to provide services to students which teach higher-level goal setting and clarification of how college 
education fits into their future, as well as positive coping strategies for managing academic anxiety and controlling worry. Targeting these deficient strategies and skills would likely promote both academic and personal-emotional adjustment. Program developers may wish to work collaboratively with faculty who teach in departments of psychology and counseling at their university or staff who provide services in college counseling centers. Positive strategies for coping with academic anxiety may be introduced in orientation seminars for all incoming students, provided in wellness promotion seminars that address self-care, provided by programs that target first-generation or other at-risk students, taught in remedial learning strategies and study skills workshops, or provided during group and/ or individual counseling for those in need of more intensive services. Research supports the effectiveness of such programs in reducing anxiety, amotivation, and psychological distress (Rajiah \& Saravanan, 2014) and increasing perceived psychosocial adjustment and stress management in college students (Conley, Travers, \& Bryant, 2013). By incorporating new understanding of relationships between learning processes, study strategies, and adaptation to college, educational researchers, post-secondary faculty, and numerous other stakeholders may prescriptively design programs to better meet the needs of entry-level students who may be at-risk due to the negative influence of impeding attitudes and anxiety on the various dimensions of college adjustment.

\section{References}

Adams, K. S., \& Proctor, B. E. (2010). Adaptation to college for students with and without disabilities: Group differences and predictors. Journal of Postsecondary Education and Disability, 22(3), 166-183.

ACT (2015). College Student Retention and Graduation Rates from 2000 through 2014. Retrieved from http://www.act.org/research/policymakers/reports/graduation. html

American College Health Association (2014). American College Health Association-National College Health Assessment II: Reference Group Executive Summary. Hanover, MD: American College Health Association. Retrieved from http://www.acha-ncha.org/docs/ACHA-NCHA-II_ReferenceGroup_ ExecutiveSummary_Spring2014.pdf

American Psychiatric Association (2013). Diagnostic and Statistical Manual of Mental Disorders (5th ed.). Washington, DC: Author.

Aspinwall, L. G., \& Taylor, S. E. (1992). Modeling cognitive adaptation: a longitudinal investigation of the impact of individual differences and coping on college adjustment and performance. Journal of Personality and Social Psychology, 63, 989-1003.

Baker, R. W., \& Siryk, B. (1984). Measuring academic motivation of matriculating college freshman. Journal of College Student Personnel, 25, 459-464.

Baker, R. W., \& Siryk, B. (1986). Exploratory intervention with a scale measuring adjustment to college. Journal of Counseling Psychology, 33, 31-38. 
Baker, R. W., \& Siryk, B. (1999). Student Adaptation to College Questionnaire (SACQ) Manual. Los Angeles, CA: Western Psychological Services.

Bean, J. P. (1980). Dropouts and turnover: The synthesis and test of a causal model of student attrition. Research in Higher Education, 12, 155-187.

Braxton, J. M. (2003). Student Success. In S. R. Komives and D. B. Woodard, Jr. (Eds.), Student Services: A Handbook for the Profession, 4th ed. (pp. 317-338). San Francisco: Jossey-Bass.

Braxton, J. M., Hirschy, A. S., \& McClendon, S. A. (2004). Understanding and Reducing College Student Departure. ASHE-ERIC Higher Education Report, 30, No. 3. Washington, DC: The George Washington University, School of Education and Human Development.

Brooks, J. H., \& DuBois, D. L. (1995). Individual and environmental predictors of adjustment during the first year of college. Journal of College Student Development, 36(4), 347-360.

Carson, A. D. (2011). Predicting student success from the LASSI for learning online. Journal of Educational Computing Research, 45(4), 399-414.

Carter, D. F., Locks, A. M., \& Winkle-Wagner, R. (2013). From when and where I enter: Theoretical and empirical considerations of minority students' transition to college. In M. B. Paulsen (Ed.), Higher Education: Handbook of Theory and Research (Vol. 28, pp. 93-150). Dordrecht, The Netherlands: Springer.

Chickering, A. W., \& Schlossberg, N. K. (2002). Getting the most out of college (2e). Upper Saddle River, N.J.: Prentice Hall.

Conley, C. S., Travers, L. V., \& Bryant, F. B. (2013). Promoting psychosocial adjustment and stress management in first-year college students: The benefits of engagement in a psychosocial wellness seminar. Journal of American College Health, 61(2), 75-86.

Crede, M., \& Niehorster, S. (2012). Adjustment to college as measured by the Student Adaptation to College Questionnaire: A quantitative review of its structure and relationships with correlates and consequences. Educational Psychology Review, 24, 133-165.

Cushman, K. (2006). First in the family: Your college years. Advice about college from first-generation students. Providence, RI: Next Generation Press.

Enochs, W. K., \& Roland, C. B. (2006). Social adjustment of college freshmen: The importance of gender and living environment. College Student Journal, 40(1), 63-73.

Institute for Women's Leadership, Rutgers University (2008). Faculty Diversity in Higher Education. Retrieved from http://iwl.rutgers.edu/documents/ njwomencount/Faculty\%20Diversity-3.pdf

Kuh, G. D., Kinzie, J., Buckley, J. A., Bridges, B. K., \& Hayek, J. C. (2006). What matters to student success: A review of the literature. Retrieved from https://nces. ed.gov/npec/pdf/kuh_team_report.pdf

Kwong, T., \& Wong, E. (2009). Institutional-level integration of the learning and study strategies inventory (LASSI). Interactive Technology and Smart Education, 6(4), 286-292. 
Li, S. T., Albert, A. B., \& Dwelle, D. G. (2014). Parental and peer support as predictors of depression and self-esteem among college students. Journal of College Student Development, 55(2), 120-138.

Marrs, H., Sigler, E., \& Hayes, K. (2009). Study strategy predictors of performance in introductory psychology. Journal of Instructional Psychology, 36(2), 125-133.

Nist, S. L., Mealey, D. L., Simpson, M. L., \& Kroc, R. (1990). Measuring the affective and cognitive growth of regularly admitted and developmental studies students using the Learning and Study Strategies Inventory (LASSI). Reading Research and Instruction, 30(1), 44-49.

Pascarella, E. T. (1980). Student-faculty informal contact and college outcomes. Review of Educational Research, 50, 545-595.

Pope, J. (2015). Full-Time, First-Year Students at VSU Represent 16 States, 15 Countries. Retrieved from https://www.valdosta.edu/about/news/ releases/2015/09/full-time,-first-year-students-at-vsu-represent-16-states,-15countries.php

Prevatt, F., Petscher, Y., Proctor, B., Hurst, A., \& Adams, K. (2006). The revised learning and study strategies inventory: An evaluation of competing models. Journal of Education and Psychological Measurement, 66, 448-458.

Rajiah, K., \& Saravanan, C. (2014). The effectiveness of psychoeducation and systematic desensitization to reduce test anxiety among first year pharmacy students. American Journal of Pharmaceutical Education, 78(9), 1-7.

Reaser, A., Prevatt, F., Petscher, Y., \& Proctor, B. (2007). The learning and study strategies of college students with ADHD. Psychology in the Schools, 44(6), 627 638.

Rummel, A., Acton, D., Costello, S., \& Pielow, G. (1999). Is all retention good? An empirical study. College Student Journal, 33, 241-246.

Schlossberg, N. K. (1981). A model for analyzing human adaptation to transition. The Counseling Psychologist, 9(2), 2-18.

Seidman, A. (2005). College Student Retention: Formula for Student Success. Connecticut: Praeger Publishers.

Spady, W. G. (1970). Dropouts from higher education: An interdisciplinary review and synthesis. Interchange, 1(1), 64-85.

Talbot, G. L. (1994). The assessment of student study skills and learning strategies to prepare teachers for academic advising tasks or the prevalidation of Motivated Strategies for Learning Questionnaire (MSLQ), Learning and Study Strategies Inventory (LASSI), and Test of Reactions and Adaptation to College (TRAC). Reports - Research/Technical.

Tinto, V. (1993). Leaving College: Rethinking the Causes and Cures of Student Attrition (2nd Ed.). Chicago: University of Chicago.

Valentine, J. C., Hirschy, A. S., Bremer, C. D., Novillo, W., Castellano, M., \& Banister, A. (2011). Keeping at-risk students in school: A systematic review of college retention programs. Educational Evaluation and Policy Analysis, 33(2), 214-234.

Warr, P., \& Downing, J. (2000). Learning strategies, learning anxiety, and knowledge acquisition. British Journal of Psychology, 91, 311-333. 
U.S. Census Bureau (2013). School Enrollment - Social and Economic Characteristics of Students. Retrieved from https://www.census.gov/hhes/school/data/cps/2010/ tables.html.

U.S. Department of Education (DOE), Institute of Education Sciences, National Center for Education Statistics (2016). Digest of Education Statistics, 51st Edition. Retrieved from https://nces.ed.gov/pubs2016/2016014.pdf

Weinstein, C. E., Acee, T. W., \& Jung, J. H. (2010). Learning strategies. In B. McGaw, P. L. Peterson, and E. Baker (eds.), International Encyclopedia of Education (3rd ed., pp. 323-329). New York: Elsevier.

Weinstein, C. E., Acee, T. W., \& Jung, J. H. (2011). Self-regulation and learning strategies. Special issue: New Directions for Teaching and Learning, 126, 45-53. Retrieved from https://onlinelibrary.wiley.com/doi/epdf/10.1002/tl.443

Weinstein, C. E., \& Palmer, D. R. (2002). Learning and Study Strategies Inventory (LASSI): User's Manual (2nd ed.). Clearwater, FL: H \& H Publishing.

Xu, Y. J., \& Webber, K. L. (2018). College student retention on a racially diverse campus: A theoretically guided reality check. Journal of College Student Retention, 20(1), 2-28. 